\title{
Hyperpigmentation of Skin (Melasma) with Solitary Oral Pyogenic Granuloma Lesion: A Case Report
}

\author{
Nitin Tomar ${ }^{1}$, Apekshaghai ${ }^{2}$, Mayur Kaushik ${ }^{3}$, Mehvish Saleem ${ }^{4}$, Mrinalini Agarwal ${ }^{4}$ \\ ${ }^{1}$ Professor, Department of Periodontology, ${ }^{2}$ Post Graduate Student, Department of Periodontology, ${ }^{3}$ Head of \\ Department, Department of Periodontology, ${ }^{4}$ Senior Lecturer, Department of Periodontology, Subharti Dental \\ College, Swami Vivekanandsubharti University
}

Abstract

The pyogenic granuloma is a relatively is an exaggerated tissue response to localised irritation or trauma. Histologically, pyogenic granuloma does not present as granuloma and is devoid of pus. It is filled with vascular channels filled with inflammatory fluid, connective tissue with immature fibroblasts and inflammatory cells scattered.It occurs most commonly in the gingiva and also lips, tongue and buccal mucosa are the other common sites. Melasma is a common skin condition hyperpigmentation of sun-exposed areas, especially on the face which is usually light to dark brown, symmetrical and irregular in appearance. Although melasma can affect all races and both sexes, it is more commonly seen in women of child-bearing age and in darkskinned individuals living in areas with intense ultraviolet (UV) radiation. Hyper pigmentation on exposed areas such as the face can be a source of cosmetic concern for patients, that can negatively impact quality of life (QOL). The present case reports a localized inflammatory hyperplasia of the maxillary gingival of a 38 year male patient who was suffering from melasma. Melasma is a disorder of hyperpigmentation with psychological impacts affecting majorly the face. Excisional biopsy of the lesion revealed findings suggestive of Pyogenic Granuloma. Excision of pyogenic granuloma may also predispose to recession of interdental soft tissue.

Keywords: Gingival, melasma, inflammatory hyperplasia, pyogenic granuloma.

\section{Introduction}

Pyogenic granuloma (PG) is an inflammatory hyperplasia describing a large range of nodular growths of the oral mucosa. ${ }^{1} \mathrm{PG}$ is a common nonneoplastic growth of the oral cavity and the first case was described by Hullihen. ${ }^{2}$ Even though various terms have been proposed earlier, Hartzell gave the current term of PG or granuloma pyogenicum. ${ }^{3}$ Melasma (from the Greek word, 'melas' meaning black) is a common, acquired, circumscribed hypermelanosis of sun-exposed skin. It presents as hyperpigmented maculesthat are hyperpigmented, symmetrical with serrations and geographical borders. The most common locations are the cheeks, upper lips, the chin and the forehead, but other sun-exposed areas may also occasionally be involved. ${ }^{4}$

Although melasma may affect any race, it is much more common in skin types that are darker than in lighter skin types and it may be more common amongst asian and hispanic races who live in areas of the world with intense solar ultraviolet exposure. Melasma is the most common pigmentary disorder among Indians. It is much more common in women during their reproductive years but about $10 \%$ of the cases do occur in men. ${ }^{5}$

Although PG is a common disease in the skin, it is rare in the gastrointestinal tract, except for the oral cavity and it is mostly found in keratinized mucosa. There are various factors such as chronic low-grade irritation, trauma, hormonal factors and certain kinds of drugswhich are proved to be the causative factors in the development of PG. Oral PGs occur in the gingival in $75 \%$ of cases and precipitating factors include poor oral hygiene, local irritants and foreign material in the gingival. Although many lesions occurring in the oral cavity have got similar appearance as PG, a detailed history, clinical examination and a proper treatment plan 
will be helpful to pinpoint the disease. ${ }^{6}$ In this article, we will present a case report of a large pyogenic granuloma of the gingiva in a 38-year-old male patient and also will review the literature in detail.

Case Report: A 38 year old male patient reported to the outpatient department of Subharti Dental College with the chief complaint of a growth in the gums in the upper left back tooth region since 2 months. The growth initially started as a small one, which progressively increased to the present size. Patient was asymptomatic 1-month back, but patient suddenly started to feel pain on eating food. The patient also stopped brushing in the area due to excessive bleeding from that region.

Soft tissue examination revealed a well-defined gingival growth in the dentulous 24-26 tooth region as a rounded vascular lesion(Figure 1).. The growth was nontender and firm on palpation and on probing; there was severe bleeding from the site. The lesion was excised with electrocautery and was sent for biopsy (Figure 2). The biopsy report suggested the growth to be $0.5 \times 0.5 \times 0.3 \mathrm{~cm}^{3}$ in size, soft to firm to consistency(Figure $3 \& 4)$. A provisional diagnosis of PG of the gingiva was given. Differential diagnosis of irritational fibroma and peripheral giant cell granuloma were given.

The patient was suffering from melasma (Figure 5) and was on medication for the same for past one month. His medication included usage of solset sunscreen gel to be applied twice a day at 8 am and 12 noon respectively, Brilanie serum and Capsule Lyos once a day for 30 days. There were relevant melasma spots on forehead and hands of the patient. Intraoral examination revealed a good oral hygiene.

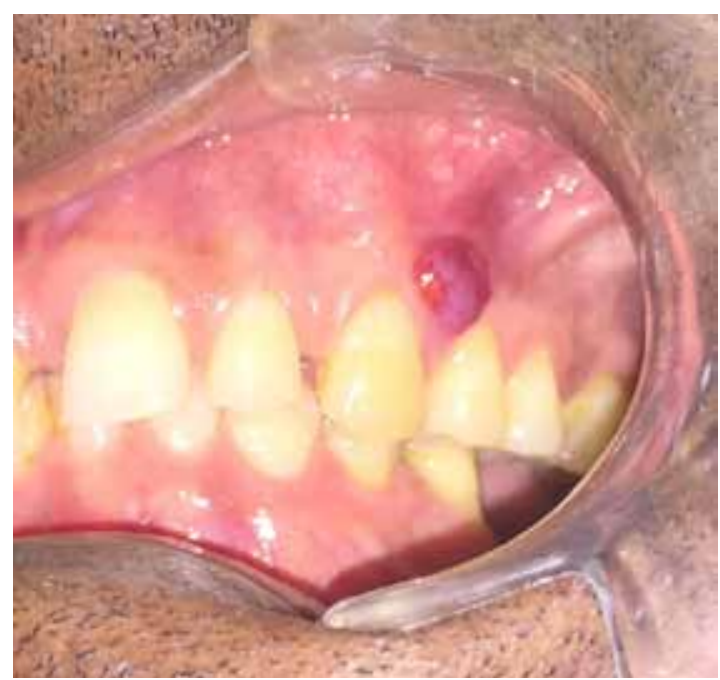

Figure 1: Vascularised growth between 23 and 24

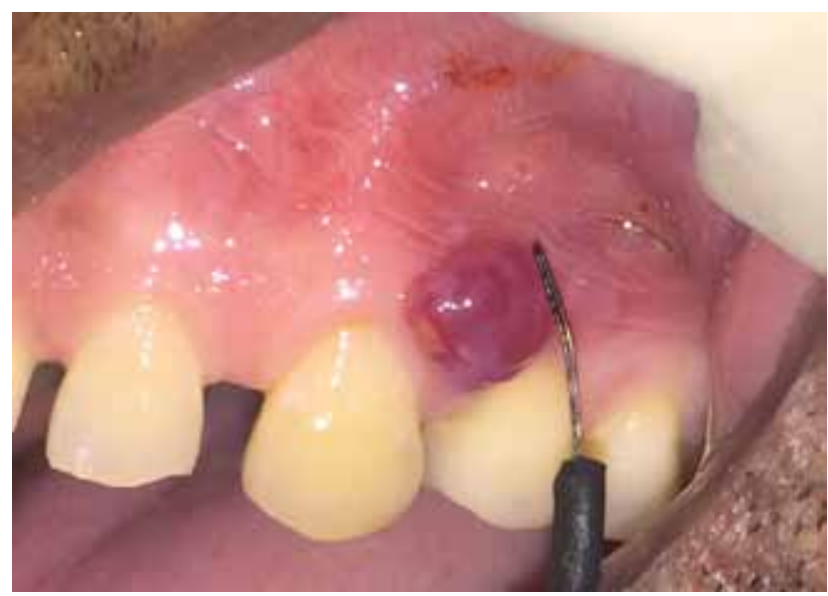

Figure 2: Excision of the growth using electrocautery

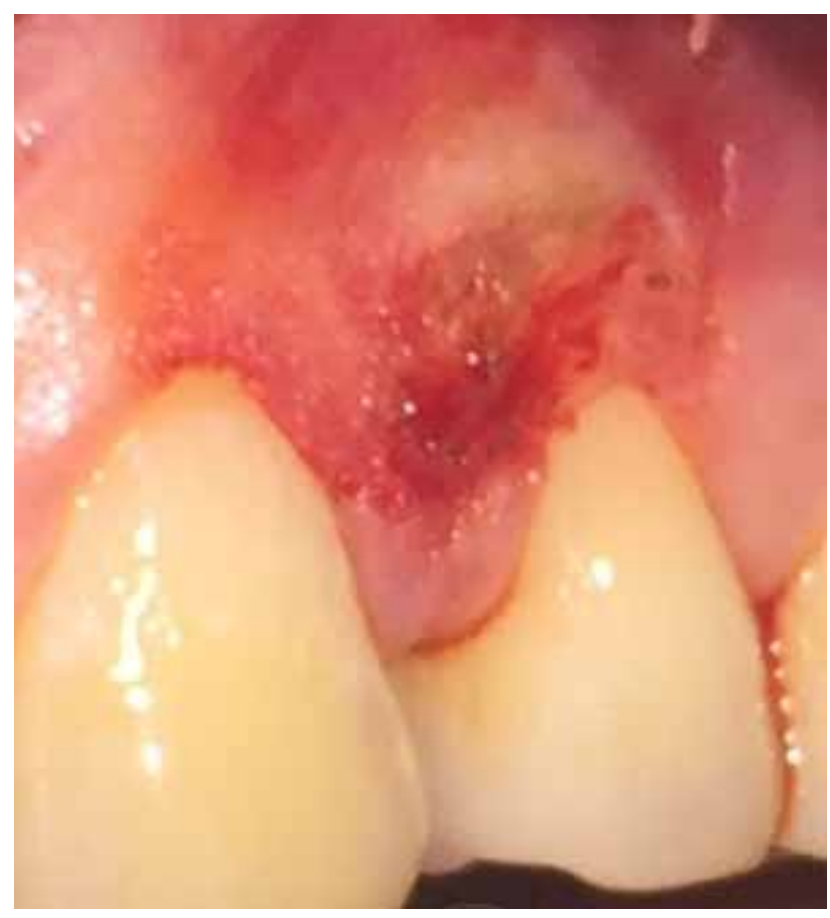

Figure 3: Immediate Post-Operative view after excision

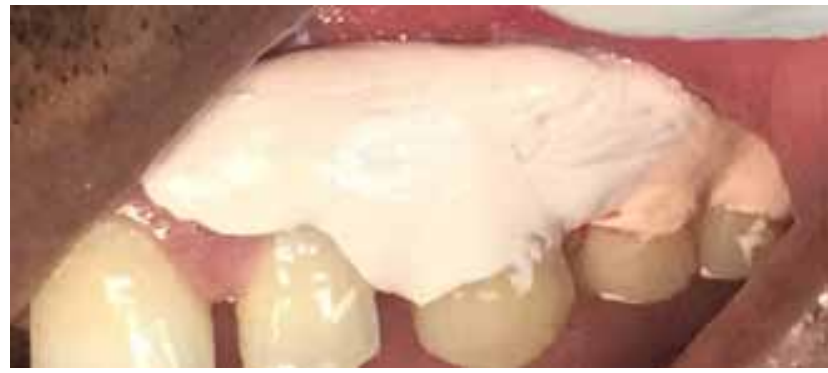

Figure 4: Application of coe-pak for the protection of excised site. 


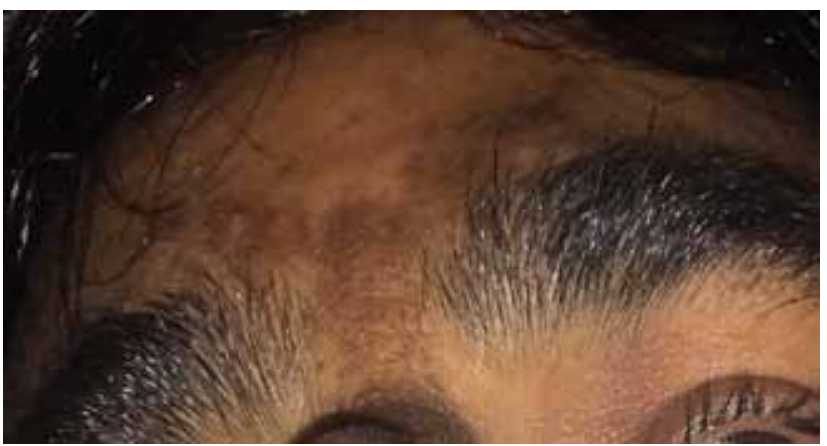

Figure 5: Melasma lesion on forehead with a V shaped appearance.

\section{Discussion}

PG is a kind of inflammatory hyperplasia and also termed as granuloma pyogenicum. PG is a misnomer because the lesion does not contain pus and is not a granuloma also. PG is caused by a known stimulant such as calculus or foreign material in the gingival crevice resulting in a proliferation of connective tissue. In addition, one-third of the lesions occur after trauma.

Ainamo et $\mathrm{al}^{7}$ suggested that routine tooth brushing habit caused repeated trauma to gingival, resulting in these lesions.Furthermore, release of variety of endogenous substances and angiogenic factors, trauma to deciduous teeth, aberrant tooth development, occlusal interferences, drugs such as cyclosporin and selection of wrong healing cap for implants are some of the precipitating factors for PG whereas Neville ${ }^{8}$ stated that oral PGs occur in all age groups, children to older adults, but frequently seen in females in the second decade due to increased levels of hormones. It appears as an elevated sessile or pedunculated growth covered with red hemorrhagic and erythematous papules and show ulcerations and is covered by a fibrinous membrane. Clinically, the lesion can be slow-growing, asymptomatic and painless, but it may also grow rapidly sometimes.

Regezi JA et $\mathrm{al}^{8}$ stated that the treatment includes surgical excision of the lesion with the removal of irritants recommended for small painless lesions. Excision of gingival lesions up to periosteum with thorough scaling and root planning of adjacent teeth to remove all visible sources of irritation whereas Jafarzadeh $\mathrm{H}$ found other treatment modalities include Nd: Yttrium-aluminumgarnet lasers, carbon dioxide lasers, flash lamp, pulse dye laser, cryosurgery, sodium tetradecyl sulphate sclerotherapy and use of intralesional steroids have been proposed by clinicians.

He also stated that incomplete excisions, failure of removal of etiological factors contribute to the recurrence of these lesions. Taira $\mathrm{JW}^{9}$ found that a recurrence rate of $16 \%$ and also a case of multiple deep satellite lesions surrounding the original excised lesion in a case of Warner Wilson James syndrome have been reported Velmann $\mathrm{A}^{10}$ said that there is a need for regular followup is also emphasized because of higher recurrence rate, especially in the gingiva.

Ortonne JP et $\mathrm{al}^{11}$ stated that sun exposure is known to be an important etiological factor in causing melasma, irrespective of sex. UV radiations increases proliferation and melanocyte activity, causing epidermal pigmentation, that occurs more intensely in melasmic areas with melasma than in unaffected skin.

Guinot $\mathrm{C}^{12}$ further substantiated by the findings that melasma usually improves during the winter and worsens during the summer months(or during other periods of intense sun exposure). Sarkar $\mathrm{R}$ et $\mathrm{al}^{13}$ found that prevalence is high in tropical regions and high elevation areas. Mahmoud $\mathrm{BH}^{14}$ recently reported infrared radiation and visible light have been found to cause melasma, although not as severely as UV radiation.

Sarkar $\mathrm{R}$ et al ${ }^{13}$ stated that according to the predominant localization of the lesions on the face, three patterns of facial melasma are recognized clinically: malar, centrofacial and mandibular. Centrofacial pattern type exhibits the forehead,upperlip cheeks, nose and chin being affected, whereas the malar pattern distributes melasma on the cheeks and nose and the mandibular pattern covers the mandibular ramus. In this case report the patient presented with the centrofacial distribution of melasma.

According to Vázquez Met $\mathrm{al}^{15}$ among men, the malar pattern is most common, representing 44.1 to 61 percent of male patients. The centrofacial variant is the seconf most common variant amongst men.

$\mathrm{O}$ brien $\mathrm{TJ}$ et al ${ }^{16}$ found that clinically, melasma is most commonly seen on the face, but melasma on other sun-exposed areas such as the arms, neck, sternal regions and back, have been seen in women. Extrafacial melasma affecting the upper body occurs mainly among elderly, menopausal women and might be associated with hormone replacement therapy. 


\section{Conclusion}

This article seeks to report a PG in the maxillary gingiva with a skin disease (Melasma). Even though PG is a relatively common presentation, it is rare to find coincinding occurrence of pyogenic granuloma with melasma. Melasma has traditionally been considered to be a pigmentation disorder of the female sex, but the occurrence in men is not uncommon.. Melasma has a multifactorial origin that is exacerbated by environmental factors such as sunlight, especially in those genetically predisposed to the condition. The etiopathogenesis of melasma in men is similar to that of women, except for hormonal factors, which are more prevalent in women.

Financial support and sponsorship Nil. Conflicts of interest There are no conflicts of interest.

Ethical Clearance: It is ethically approved by the eithical committee of swami Vivekanandsubharti University.

\section{References}

1. Neville BW, Damm DD, Allen CM, Bouquot JE. 2nd ed. Philadelphia: Saunders; 2002. Oral and Maxillofacial Surgery; pp. 447-9.

2. Tomar N, Jain A. Pyogenic granuloma. A case report. Uttar Pradesh State Dent J 2010;28:193-5.

3. Eversole LR. Clinical Outline of Oral Pathology. Diagnosis and Treatment. $3^{\text {rd }}$ ed. Hamilton: BC Decker; 2002. p. 113-4.

4. Hullihen SP. Case of aneurism by anastomosis of the superior maxillae. Am J Dent Sci 1844;4:160-2.

5. Hartzell MB. Granuloma pyogenicum. J Cutan Dis Syph1904;22:520-5.

6. Bandyopadhyay D. Topical treatment of melasma. Indian J Dermatol. 2009;54:303-9.
7. Ainamo J. The effect of habitual toothcleansing on the occurrence of periodontal disease and dental caries. SuomHammaslaakToim 1971;67:63-70

8. Regezi JA, Sciubba JJ, Jordan RC. Oral Pathology and CLINICAL Pathological Considerations. 4 th ed. Philadelphia: W B Saunders; 2003. p. 115-6.

9. Taira JW, Hill TL, Everett MA. Lobular capillary hemangioma (pyogenic granuloma) with satellitosis. J Am Acad Dermatol 1992;27 (2 Pt 2):297-300

10. Vilmann A, Vilmann P, Vilmann H. Pyogenic granuloma: Evaluation of oral conditions. Br J Oral Maxillofac Surg1986;24:376-82.

11. Ortonne JP, Arellano I, Berneburg M, et al. A global survey of the role of ultraviolet radiation and hormonal influences in the development of melasma. J Eur Acad Dermatol Venereol. 2009;23:1254-1262.

12. Guinot C, Cheffai S, Latreille J, et al. Aggravating factors for melasma: a prospective study in 197 Tunisian patients. J Eur Acad Dermatol Venereol. 2010;24:1060-1069.

13. Sarkar R, Jain RK, Puri P. Melasma in Indian males. Dermatol Surg. 2003;29:204

14. Mahmoud BH, Ruvolo E, Hexsel CL, et al. Impact of long-wavelength UVA and visible light on melanocompetent skin. J Invest Dermatol. 2010;130:2092-2097

15. Vazquez $\mathrm{M}$, Maldonado $\mathrm{H}$, Benmaman $\mathrm{C}$, et al. Melasma in men. a clinical and histologic study. Int J Dermatol. 1988;27:25-27

16. O'Brien TJ, Dyall-Smith D, Hall AP. Melasma of the forearms. Australas J Dermatol. 1997;38:3537. 